\title{
The relationship between spiritual health and happiness among the students of health Sciences in Guilan University of Medical Sciences
}

\section{Parisa Kasmaei}

Guilan University of Medical Sciences

\section{Esmaeil Fattahi}

Tehran University of Medical Sciences

Roghaye Farhadi Hassankiadeh ( $\nabla$ r.farhadikia@gmail.com )

Kermanshah University of Medical Sciences https://orcid.org/0000-0003-3982-3680

\section{Afshin Almasi}

Kermanshah University of Medical Sciences

\section{Arash Ziapour}

Kermanshah University of Medical Sciences

\section{Farzaneh Kasraei}

Shiraz University of Medical Sciences Faculty of Dentistry

\section{Ayoob Rastegar}

Sabzevar University of Medical Sciences

\section{Zahra Ensandoost Roodpishi}

Guilan University of Medical Sciences

Mohtaram Nasirizadeh

Guilan University of Medical Sciences

Mahsa Rostamtabar Ghasemabadi

Guilan University of Medical Sciences

\section{Research}

Keywords: Spiritual Health, Happiness, Students, Spirituality

Posted Date: January 6th, 2020

DOl: https://doi.org/10.21203/rs.2.20114/v1

License: (1) (1) This work is licensed under a Creative Commons Attribution 4.0 International License.

Read Full License 


\section{Abstract}

Background: Spirituality and spiritual health are important concepts among human societies, and the relation of these concepts to other scientific ones is important for health professionals. The purpose of this study is to investigate the relationship between spiritual well-being and happiness among the students of health sciences of Guilan University of Medical Sciences.

Methods: This is a cross-sectional and descriptive-analytic study carried out among 322 students through census sampling method. The Spiritual Health Questionnaire (SWBS) was made by Pulotsin and Ellison in 1982 and used to measure spiritual well-being. Oxford Happiness Questionnaire $(\mathrm{OHI})$ was used to measure happiness designed in 2007 by Argyle. Validity and reliability of two questionnaires are higher than 0.90. Cronbach's alpha in each dimension of spiritual well-being and also happiness in the present study was higher than 0.7 .

Results : The mean and standard deviation of spiritual health were $55.82 \pm 4.71$ and the mean and standard deviation of students' happiness was $60.88+-12.9$. There is no statistical correlation between spiritual health with any of the demographic variables. It means that the average spiritual health is not significantly different at different ages or between single students and married students.

Conclusion: The results showed that there is a positive and significant relationship between spiritual wellbeing and happiness. Also, there is a meaningful relationship between all aspects of spiritual health with happiness. The findings of this research illustrate the happiness is reduced by increasing the average age.

\section{Background}

Spirituality is one of the fundamental concepts among humans and has been considered remarkably by psychologists and mental health professionals in recent decades as a global phenomenon [1, 2]. The most important dimensions of health are physical, psychological, spiritual, emotional and social aspects.

In fact, spiritual wellbeing is the newest recognized health dimension that has been placed alongside other dimensions of health [3]. Most health models focus on spiritual health [4]. Spiritual health is characterized by features such as stability in life, feelings of association with "self", God, society, and other creatures and being purposeful in life [5-8]. Spiritual health involves three dimensions including cognition, emotions, and action. Spirituality indicators are not just the part of psychological behaviors or emotions, such as internal satisfaction or internal peace, but also spiritual well-being focuses on all human life aspects [9-11] Based on the conducted studies, spiritual health can affect the quality of life [12].

Another factor associated with spiritual health is the happiness that results from personal judgement about how to live. This judgment is not imposed from the outside, but rather a personal and internal affair that is affected by the positive excitement. Happiness is one of the most important ways of 
prevention and treatment of mental disorders [13-15]. It is a condition of the cheerfulness or joy (positive emotions), being satisfied with life, and the lack of depression and anxiety (negative factors) $[16,17]$.

An extraordinary force existing in spiritual health gives the person a spiritual power and distracts him/her from anxiety and worries $[18,19]$. In sum, it can be said that spirituality and spiritual health play a major role in the mental and physical health of individuals and it is considered as a useful way to deal with psychological problems, including depression $[20,21]$. Depression is a common disorder that is one of the most serious physical and mental illnesses and its prevalence rate in the world is $10-20 \%$ per year. Approximately $15 \%$ of the total population experiences a period of major depression in an episode of their lives $[22,23]$. Students' populations are prone to be depressed and depressed students face more problems in their curriculum, and their grades are lower than other their counterparts [24]. The results of published studies in Iran indicate that prevalence of depression among university students is between $36 \%$ and $66 \%$.Around 2 to $5 \%$ of them suffering from severe type of disorder $[25,26]$. Also, in some studies, happiness and its role in satisfying students' lives are investigated $[27,28]$. Promoting spiritual well-being in universities is often recommended. Therefore, in addition to the skills required for students, it is also necessary to gain spiritual skills $[29,30]$. The purpose of this study was to determine the spiritual health and its relation with happiness among the students of health sciences of Guilan University of Medical Science. The determination of the relationship between each aspect of spiritual health with happiness in the studied population, could be the basis of planning for promotion of happiness among students, because investing in universities to improve the spiritual health of students can lead to a reduction in depression, increasing happiness, and, ultimately, academic achievement among them.

\section{Methods}

\section{Study design}

This is a descriptive-analytic and cross-sectional study. The statistical population included all students of Health Sciences studying in Guilan University of Medical Sciences in the first semester of the academic year 2016-2017. The students were entered into the study by census method. The number of investigated students was 323. The data collection tool was a questionnaire. The SWBS spiritual health questionnaire designed by Pulotsin and Ellison in 1982 and used to measure the spiritual health. It consisted of 20 questions categorized based on Likert's 5-choice (totally agree, agree, no opinion, opposite, totally opposite). The score for each of the responses was scaled from 1 to 5 . The spiritual health score is the sum of the scores of three dimensions of cognition, action, and emotion ranging from 120 - 20. The Farsi version of this scale was adapted and divided into these dimensions. In terms of the positive verb, the "totally agreeable" scores 5 and the "totally opposite" scores 1 . The expressions with a negative verb lead to reverse the scores. This questionnaire has been used by other scholars in Iran and its validity and reliability have been verified [31]. To measure happiness, Oxford Happiness Standard Questionnaire (OHI) was used developed by Argyle in 2001. The questionnaire contains 29 quadrants questions (always, sometimes, rarely, and at all) and the scores for them are 4, 3, 2, and 1, respectively. The range of happiness score is between $87-0$. The validity and reliability of this questionnaire were 
measured by AliPour and Agah Harris. The results showed that it has appropriate validity and reliability for measuring the happiness in the Iranian society [18]. Also, The Farsi version of this scale was adapted. According to Mozafari Nia and his colleagues' findings, validity and reliability of the two questionnaires are higher than 0.90 [32]. Cronbach's alpha in each dimension of spiritual well-being and also happiness dimensions in the mentioned study were higher than 0.7. Exclusion criterion was the unwillingness to participate in the study. SPSS 16 and descriptive statistical methods including frequency distribution and mean indices, standard deviations and analytical statistics including Spearman correlation, MannWhitney and Kruskal tests were used in order to analyze the data,

\section{Results}

In this study, 93\% of students were females and the mean and standard deviation of students' age was $24.61 \pm$ 7.62. 70 percent of students were single and their average level of interest to their study was up to 80 percent. $82 \%$ of them were domestic in that region (Table 1)

Table 1 Demographic information of the subjects 


\begin{tabular}{|c|c|c|c|}
\hline Percentage & Abundance & Category & Variable \\
\hline 14.0 & 45 & Male & Gender \\
\hline 86.0 & 277 & Female & \\
\hline 33.5 & 108 & Under 20-year-old & Age \\
\hline 48.1 & 155 & Between 20-30-year-old & \\
\hline 18.3 & 59 & More than 30-year-old & \\
\hline 69.9 & 222 & single & Marital status \\
\hline 31.1 & 100 & married & \\
\hline 19.6 & 63 & Discontinued Bachelor of Science & Degree of education \\
\hline 74.8 & 241 & Bachelor of Science & \\
\hline 5.6 & 18 & Master of Science & \\
\hline 42.2 & 136 & Public Health & Major of study \\
\hline 29.2 & 94 & Health Professional & \\
\hline 25.2 & 81 & Environmental Health & \\
\hline 3.4 & 11 & Health Education & \\
\hline 22.8 & 26 & 2013 & Entrance year of Study in university \\
\hline .9 & 1 & 2014 & \\
\hline 39.5 & 45 & 2015 & \\
\hline 7.0 & 8 & 2016 & \\
\hline 29.8 & 34 & 2017 & \\
\hline 82.0 & 264 & Indigenous & Address \\
\hline 18.0 & 58 & Non-native & \\
\hline 24.6 & 92 & Personal home & Residential home status \\
\hline 28.6 & 122 & Alongside parents & \\
\hline 37.9 & 8 & Private accommodation & \\
\hline 2.5 & 84 & Government dormitory & \\
\hline 5.0 & 16 & Rental house & \\
\hline 8.7 & 28 & Too much & The amount of interest in the field of study \\
\hline 33.9 & 109 & Much & \\
\hline 37.3 & 120 & Medium & \\
\hline 17.1 & 55 & Low & \\
\hline 3.1 & 10 & Very little & \\
\hline 6.5 & 21 & Under 500 thousand tomans & \\
\hline 25.2 & 81 & Between 500 thousand tomans to 1 million $\mathrm{T}$ & Household income \\
\hline 43.2 & 139 & Between 1 million and 2 million Tomans & \\
\hline 25.1 & 81 & Two million Tomans and up & \\
\hline
\end{tabular}

The mean and standard deviation of spiritual health was 55.824 .71 , and the mean and standard deviation of students' happiness was 60.88 12.99. The following table describes the dimensions of spiritual health.

Table 2 Descriptive Information: Spiritual Health and Happiness and Its Dimensions 


\begin{tabular}{ccccc}
\hline Variable & Minimum & Maximum & Mean & Std. Deviation \\
\hline Mental Health & 38.00 & 68.00 & 55.82 & 4.71 \\
Cognitive Dimension & 8.00 & 30.00 & 17.14 & 2.23 \\
Emotional Dimension & 16.00 & 33.00 & 25.19 & 2.64 \\
Happiness Dimension & 30.00 & 98.00 & 60.88 & 12.99 \\
Life Satisfaction & 8.00 & 37.00 & 16.39 & 4.33 \\
The scope of self-respect & 7.00 & 26.00 & 15.10 & 3.72 \\
The field of welfare & 5.00 & 20.00 & 11.58 & 2.84 \\
Satisfaction & 4.00 & 14.00 & 7.59 & 2.07 \\
Positive mood field & 5.00 & 16.00 & 10.22 & 2.43 \\
\hline
\end{tabular}

There was no statistically significant relationship between spiritual health with any of the demographic variables, which means that the mean of spiritual health in different ages was not significantly different. Besides, spiritual health was not significant between single students and married people.

The following table shows the correlation coefficient between spiritual health and its dimensions and happiness.

Table 3 Spearman correlation between spiritual wellbeing and happiness

\begin{tabular}{|c|c|c|c|c|c|c|c|}
\hline \multicolumn{2}{|c|}{ Variable } & \multirow{2}{*}{$\begin{array}{l}\text { Happiness } \\
.239 *\end{array}$} & \multirow{2}{*}{$\begin{array}{c}\text { Life } \\
\text { satisfaction } \\
.102 *\end{array}$} & \multirow{2}{*}{$\begin{array}{c}\text { The scope of } \\
\text { self-respect } \\
.154^{* *}\end{array}$} & \multirow{2}{*}{$\begin{array}{c}\text { The field of } \\
\text { welfare } \\
.143^{* *}\end{array}$} & \multirow{2}{*}{$\begin{array}{l}\text { Satisfaction } \\
.095^{*}\end{array}$} & \multirow{2}{*}{ 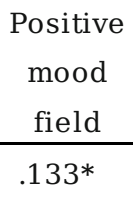 } \\
\hline spiritual health & Correlation & & & & & & \\
\hline & Coefficient & & & & & & \\
\hline \multirow{4}{*}{$\begin{array}{l}\text { Cognitive } \\
\text { dimension }\end{array}$} & Sig. (2-tailed) & .013 & .049 & .006 & .010 & .048 & .017 \\
\hline & Correlation & $.323 *$ & $.136 *$ & $.428 *$ & $.923 *$ & $.223 *$ & $.901 *$ \\
\hline & Coefficient & & & & & & \\
\hline & Sig. (2-tailed) & .05 & .043 & .044 & .005 & .048 & .007 \\
\hline \multirow{3}{*}{$\begin{array}{l}\text { Emotional } \\
\text { dimension }\end{array}$} & Correlation & $.197 * *$ & $.186^{* *}$ & $.213^{* *}$ & $.157 * *$ & $.127 *$ & $.178 * *$ \\
\hline & Coefficient & & & & & & \\
\hline & Sig. (2-tailed) & .000 & .001 & .000 & .005 & .038 & .001 \\
\hline \multirow{3}{*}{$\begin{array}{c}\text { Action } \\
\text { dimension }\end{array}$} & Correlation & $.172 * *$ & $.095 *$ & $.221 * *$ & $.174 * *$ & $.099 *$ & $.140 *$ \\
\hline & Coefficient & & & & & & \\
\hline & Sig. (2-tailed) & .002 & .050 & .000 & .002 & .045 & .012 \\
\hline
\end{tabular}

Table 4 Correlation of spiritual health scores and happiness with demographic variables

\begin{tabular}{|c|c|c|c|c|c|c|c|c|c|}
\hline \multicolumn{2}{|c|}{ Variable } & \multirow{2}{*}{$\begin{array}{c}\text { Gender } \\
324 .\end{array}$} & \multirow{2}{*}{$\begin{array}{c}\text { Marital } \\
\text { status }\end{array}$} & \multirow{2}{*}{$\begin{array}{c}\text { Residential } \\
\text { home status } \\
996 .\end{array}$} & \multirow{2}{*}{$\begin{array}{c}\text { age } \\
\text { category } \\
044 .\end{array}$} & \multirow{2}{*}{$\begin{array}{c}\text { degree of } \\
\text { education } \\
048 .\end{array}$} & \multirow{2}{*}{$\begin{array}{l}\text { The a mount of } \\
\text { interest in the field } \\
\text { of study } \\
54 .\end{array}$} & \multirow{2}{*}{$\begin{array}{c}\text { Address } \\
85 .\end{array}$} & \multirow{2}{*}{$\begin{array}{c}\begin{array}{c}\text { Household } \\
\text { income }\end{array} \\
48 .\end{array}$} \\
\hline $\begin{array}{l}\text { Spiritual } \\
\text { health }\end{array}$ & $\begin{array}{c}\text { p- } \\
\text { value }\end{array}$ & & & & & & & & \\
\hline Happiness & & 378. & 000. & 79. & 005. & 000. & 000. & 014. & 333. \\
\hline
\end{tabular}

\section{Discussion}


The aim of this study was to determine the relationship between spiritual well-being and happiness among students of the Faculty of Health of Guilan University of Medical Sciences. The results showed that there was a positive and significant relationship between spiritual well-being and happiness. There is also a significant relationship between all aspects of spiritual health with happiness that is consistent with the study of Mozafari Nia et al. [32]. In this investigation, there was a significant relationship between spiritual well-being and marital status, which was consistent with the studies of Mozafari Nia et al. and Ebadi et al $[32,33]$.

The results of this research indicated that spiritual well-being had significant relationship with age group and decreased with age increase. The highest level of health belonged to the age group under the age of 20 with the mean (standard deviation) of 56.56 (4.15), then, the age ranging from 20 to 30 years old with a mean (standard deviation) of 55.59 (4.80) and the lowest level of spiritual wellbeing for the group over 30 years of age with a value of 54.89 (5.26). These results were consistent with the results of the Tavan 's et al's research [34]. Spiritual health had a significant relationship with marital status, so that the average spiritual health in single students $(56.10 \pm 4.74)$ was more than married $(55.20 \pm 4.61)$ ones. It is compatible with the study of Tavan and colleagues [34].

In this study, there was no relationship between gender and spiritual well-being, which is consistent with the studies of Asaroodi and Allah Bakhshian $[35,36]$. There was no relationship between educational level and housing situation with spiritual health, which was matched with Mozafari Nia et al's investigation [32]. The results of this study illustrated that age had the negative relation between happiness and the increasing of age. This result was consistent with the study of Bradburn [37] Overall, the relationship between age and happiness has not been clearly identified. In other studies, positive results and negative correlations were found. Some investigations also showed no correlation [38]. The results of Bradburn's study indicated that the level of happiness decreased by increasing every ten years. 8 percent of people are not happy at the age of 20 , and for people at the age of 50 , this percentage is up to 17. Also, the results of this study demonstrated that there was is not the significant relationship between happiness and gender, which is in agreement with the results of the study of Kiwomah Hanankan [39]. In this research ,there was a significant relationship between happiness and marital status, which was consistent with the results of the studies of Mastkasa and Abedi $[33,40]$. In their research, they revealed that the happiness of married people was greater than that of single people. The findings of this study showed significant relationship between interest in the field of study and happiness. There was a significant relationship between happiness and educational level which was consistent with Abedi et al's investigation. In general, it cannot be said that the higher the education, the higher the happiness. But as people with higher education may earn at least as much as their basic living needs, their low level of happiness might not be the case. But there is no definite relationship between education and happiness [41].

\section{Conclusion}


The results showed positive and significant relationship between spiritual well-being and happiness. Also, there was a meaningful relationship between all aspects of spiritual health with happiness. The results of this investigation illustrated that as the average age increased, happiness decreased. Considering the importance of happiness for students, it is suggested that spiritual well-being should be considered as one of the important factors in increasing the happiness of student.

\section{Abbreviations}

SH: Spiritual Health; H: Happiness; GUMS: Guilan University of Medical Sciences

\section{Declarations}

\section{Acknowledgments}

Our grateful thanks go to all participants in the present study.

\section{Declarations}

\section{Authors'contributions}

EF and PK contributed to the design, RFH, AZ and AA statistical analysis, participated in most of the study steps. FK and MN and MRG prepared the manuscript. E R and AR assisted in designing the study, and helped in the, interpretation of the study. All authors have read and approved the content of the manuscript.

\section{Funding}

There was no source of funding.

\section{Availability of data and materials}

Authors report that the data supporting their findings can be publicly shared.

\section{Ethics approval and consent to participate}

Not declared. 


\section{Consent for publication}

Not applicable.

\section{Competing interests}

The authors declare that they have no competing interests

\section{Author details}

${ }^{1}$ Assistant Professor, Department of Health Education and Promotion, Research Center of Health and Environment, School of Health, Guilan University of Medical Sciences, Rasht, Iran. ${ }^{2}$ Ph.D. Candidate. Education and Health Promotion, School of Health, Iran University of Medical Sciences (IUMS), Tehran, Iran. ${ }^{3}$ Clinical Research Development Center, Imam Khomeini and Mohammad Kermanshahi and Farabi Hospitals, PHD Student, Department of Biostatistics, School of Health, Kermanshah University of Medical Sciences, Kermanshah, Iran. ${ }^{4} \mathrm{PhD}$ Student of Health Education and Health Promotion, Health Institute, Kermanshah University of Medical Sciences, Kermanshah, Iran. ${ }^{5} \mathrm{BSc}$ of Nursing, Ebnesina Hospital, Shiraz University of Medical Sciences, Shiraz, Iran. ${ }^{6}$ Department of Environmental Health Engineering, School of Public Health, Sabzevar University of Medical Sciences, Sabzevar, Iran. ${ }^{7}$ BSc of public health, School of Health, Guilan University of Medical Sciences, Rasht, Iran.

\section{References}

1. Delgado C. A discussion of the concept of spirituality. Nursing science quarterly. 2005;18(2):157-62.

2. West W. Psychotherapy \& spirituality: Crossing the line between therapy and religion: Sage; 2000.

3. Asar RAG, Jalilvand M, Oudi D, Akaberi A. The relationship between spiritual well-being and life satisfaction in the nursing staff of Mashhad Hasheminezhad Hospital (2011). 2012.

4. Smith J, McSherry W. Spirituality and child development: a concept analysis. J Advan Nurs. 2004;45(3):307-15.

5. Carven R, Hirnle C. Fundamental of nursing human health and function, Unit 7. Health Percept Health Manag. 2009:658-71.

6. Gomez R, Fisher JW. Domains of spiritual well-being and development and validation of the Spiritual Well-Being Questionnaire. Person Individ Differen. 2003;35(8):1975-91.

7. Safayi RI, Karimi L, Shomoossi N, Ahmadi TM. The relationship between spiritual well-being and mental health of university students. 2011. 
8. Solhi M, Fattahi E, Pouresmaeil M, Darvishigilan H, Rastaghi S. Letter to Editor: A Comprehensive Definition of Spiritual Health. 2019.

9. Galek K, Flannelly KJ, Ellison CG, Silton NR, Jankowski KR. Religion, meaning and purpose, and mental health. Psychology Religion Spiritual. 2015;7(1):1-9.

10. Marzband R, Zakavi AA. Indicators of spiritual health based on Quran perspective. Med Ethics J. 2016;6(20):69-99.

11. Kavousi E, Khazaei Z, Amini A, Fattahi E, Pnahi A, Sohrabivafa M, et al. Promoting behaviors of healthiness in two domains of physical activity and nutrition statue in high school students. Int $J$ Pediatr. 2017;5(5):4839-47.

12. Panahi R, Ahmadi A, Amjadian M, Khasi B, Noori E, Ghajari H, et al. A study on the relationship between spiritual health and quality of life in patients with type 2 diabetes mellitus. Chronic Diseas $\mathrm{J}$. 2019:73-9.

13. Hills P, Argyle M. Happiness, introversion-extraversion and happy introverts. Personality Individ Differ. 2001;30(4):595-608.

14. Fredrickson BL. The role of positive emotions in positive psychology: The broaden-and-build theory of positive emotions. Am Psychol. 2001;56(3):218-26.

15. Rahaei Z, Yarmohammadi P, Fatahi E, Mehri H, Kasiri N. The Relationship between Demographic Variables with General Health and Quality of Life in Students of Islamic Azad University, Sabzevar Branch, Iran. Qom Univ Med Sci J. 2015;9(10):40-7.

16. Tajabadi R, Farbod AAA. Relationship between religious orientation and components of emotional intelligence among medical students of Shahid Beheshti University of Medical Sciences. J Res Religion Health. 2017;4(1):79-92.

17. Shojaezadeh D, Peyman N, Shakeri MT, Nedjat S, Hakkak AM, Taghdisi MH, et al. Pictorial Health Warning Labels on Cigarette Packages: An Investigation on Opinions of Male Smokers. Iran Red Crescent Med J. 2014;16(3): e14879.

18. Chavoshian SA, Moeini B, Bashirian S, Feradmal J. The role of spiritual health and social support in predicting nurses' quality of life. J Educ Community Health. 2015;2(1):19-28.

19. Csikszentmihalyi M, Seligman ME. Positive psychology: An introduction. Am Psychol. 2000;55(1):514.

20. Mahbobi M, Etemadi M, Khorasani E, Ghiasi M. The relationship between spiritual health and social anxiety in chemical veterans. J Mil Med. 2012;14(3):186-91.

21. Hosseini SH, Rajabzadeh R, Nosrati H, Naseri F, Toroski M, Mohaddes Hakkak H, et al. Prevalence of medicinal herbs consumption in pregnant women referring to Bojnurd health care centers. Iran $\mathrm{J}$ Obstetr, Gynecology Infert. 2017;20(9):33-40.

22. Burns D. Psychological depression. Tehran: Owhadi Publication. 1996.

23. Hakkak HM, Joveini H, Rajabzadeh R, RobatsarpooshI D, Tori NA, Haresabadi M, et al. Health Literacy Level and Related Factors among Pregnant Women Referring to Bojnord Health Centers in 2017. Int J 
Pharmaceut Res. 2019;11(1):151-8.

24. Laurin K, Kay AC, Moscovitch DA. On the belief in God: Towards an understanding of the emotional substrates of compensatory control. J Experim Soc Psychology. 2008;44(6):1559-62.

25. Shadman N, Raoof M, Amanpour S, Mahdian M, Haghani J, Parizi MT. Stress, Anxiety, and Depression and Their Related Factors Among Dental Students: A Cross-Sectional Study from Southeast of Iran. Strid Developm Med Educ. 2019;16(1):18-23.

26. Organization WH. Report on the interregional meeting on leishmaniasis among neighbouring endemic countries in the Eastern Mediterranean, African and European regions, Amman, Jordan 2325 September 2018. World Health Organization, Regional Office for the Eastern Mediterranean; 2019.

27. Deb S, Thomas S, Bose A, Aswathi T. Happiness, Meaning, and Satisfaction in Life as Perceived by Indian University Students and Their Association with Spirituality. J Religion Health. 2019:1-17.

28. Salmani S, Biderafsh A, Arani ZA. The Relationship Between Spiritual Development and Life Satisfaction Among Students of Qom University of Medical Sciences. J Religion Health. 2019:1-8.

29. Koenig H, Koenig HG, King D, Carson VB. Handbook of religion and health: Oup Usa; 2012.

30. Rahaei Z, Yarmohammadi P, Fattahi E, Mehri H, Kasiri N. The relationship between demographic variables with general health and quality of life in students of Islamic Azad University, Sabzevar Branch, Iran. 2015.

31. Rahimi N, Nouhi E, Nakhaee N. Spiritual well-being and attitude toward spirituality and spiritual care in nursing and midwifery students. Iran J Nurs. 2013;26(85):55-65.

32. Mozafarinia f, Shokravi FA, hydarnia A. Relationship between spiritual health and happiness among students. Iran J Health Educ Health Promot. 2014;2(2):97-108.

33. Abedi MR, Mirshah Jafari E, Liaghatdar MJ. Standardization of the oxford happiness inventory in students of isfahan university. Iran J Psychiatry Clin Psychology. 2006;12(2):95-100.

34. Avan h, Taghinejad H, Sayehmiri K, Yary Y, Fathizadeh H, Saraby A, et al. Spiritual health of nursing students. Islam Health J. 2015;2(1):26-32.

35. Allahbakhshian M, Jaffarpour M, Parvizy S, Haghani H. A survey on relationship between spiritual wellbeing and quality of life in multiple sclerosis patients. Zahedan J Res Med Sci. 2010;12(3):29-33.

36. Asarrodi A. Relationship of spiritual health and life quality of nurses. 2011.

37. Bradburn NM. The structure of psychological well-being. 1969.

38. Sahraian A, Gholami A, Omidvar B. The relationship between religious attitude and happiness in medical students in Shiraz University of Medical Sciences. Horizon Med Sci. 2011;17(1):69-74.

39. Koivumaa-Honkanen H, Kaprio J, Honkanen RJ, Viinamäki H, Koskenvuo M. The stability of life satisfaction in a 15-year follow-up of adult Finns healthy at baseline. BMC Psychiatry. 2005;5(1):410.

40. Mastekaasa A. Marital status, distress, and well-being: An international comparison. J Compar Family Stud. 1994;25(2):183-205. 
41. Siamian H, Naeimi OB, Shahrabi A, Hassanzadeh R, Abazari MR, Khademloo M, et al. The status of happiness and its association with demographic variables among the paramedical students. $\mathrm{J}$ Mazandaran Univ Med Sci. 2012;21(86):159-66. 